\title{
Enhancement of tartaric acid modified washing solutions for lead decontamination of tropical soils
}

\author{
Effiong Ukorebi ETIM*
}

\author{
Department of Chemistry, University of Ibadan, Ibadan, Nigeria
}

\begin{abstract}
Tartaric acid is generally not an effective soil washing solution, hence this study focuses on enhancing its usage for soil- $\mathrm{Pb}$ decontamination. Three tropical soil types (sandy, clay and loamy) with different lead concentrations were subjected to single batch washing using $0.01,0.1,0.5$ and $1 \mathrm{M}$ tartaric acid with $5 \%$ and $10 \% \mathrm{KCl}$ modification at $3 \%$ soil-pulp-density for 2, 6, 12 and $24 \mathrm{~h}$ washing time. The optimum washing conditions were $1 \mathrm{M}$ tartaric acid at $24 \mathrm{~h}$ washing time, with $\mathrm{Pb}$ removal efficiency: sandy- 94.3\%, clay-67.6\% and loamy-36.8\%. Modification of tartaric acid with $5 \%$ and $10 \% \mathrm{KCl}$ brought about some degree of enhancement of $\mathrm{Pb}$ removal efficiency especially for clay and loamy soils. Removal efficiency for $5 \% \mathrm{KCl}$ modification were: sandy-97.9\%, clay-96.2\% with $1 \mathrm{M}$ tartaric acid at $24 \mathrm{~h}$ washing time, loamy-76.7\% for $0.5 \mathrm{M}$ tartaric acid. Similarly, $10 \% \mathrm{KCl}$ modification were: sandy-96.7\%, clay-97.2\% for $1 \mathrm{M}$ tartaric acid at $24 \mathrm{~h}$, loamy-82.1\% for $0.5 \mathrm{M}$ tartaric acid. Removal efficiency was soil concentration dependent. Generally, removal efficiency increased with increasing tartaric acid concentrations and washing time. Tartaric acid washing is promising and recommended in events of moderate contamination and $10 \% \mathrm{KCl}$ modification in event of high level contamination. Further study is needed on enhancing very low concentrations of tartaric acid for large scale applications.
\end{abstract}

Keywords: soil remediation; lead; tartaric acid; soil contamination.

\section{Introduction}

Toxic trace metals undoubtedly have continued to raise attention due to greater understanding of their toxicological importance in the environment [1-3]. Particularly, soil-Pb content has dramatically increased in recent decades and often anthropogenically derived and non-biodegradable [4-7]. In environment, toxic $\mathrm{Pb}$ causes several adverse effects on biota. Soils serve as final repository of $\mathrm{Pb}$ in environment and also major food source for most biota, therefore, contaminated soils need to be cleaned to avoid/reduce contacts between the two [8, 9]. Several methods ranging from physical, chemical and biological have been adopted for toxic $\mathrm{Pb}$ removal from soils [10]. Among these methods, soil washing is particularly promising due to its simplicity, viability and efficiency [11-15]. Several studies have focused on the use of washing reagents such as inorganic and organic acids, chelating agents, bio-surfactants and composites with significant effectiveness in $\mathrm{Pb}$ removal from soils [13, 16-19]. These reagents, however, have deleterious effects on soil ecosystem in most cases rendering the soil sterile.

Greater emphases have now been placed on the use of low molecular weight organic acids (LMWOAs) which are more biodegradable and have less secondary ecological risk, because they can be produced by plant roots or microorganisms [20, 21]. Some LMWOAs such as acetic, citric, oxalic and tartaric acids have recently been used for soil washing [3, 13, 22-24]. However, their removal efficiency is not as effective as inorganic acids or chelating agent. Hence efforts have to be made towards achieving higher removal efficiency. Tartaric acid is one promising LMWOAs for soil washing due to its chelating characteristics [25]. It is a non-humified acid which forms naturally in soils from decaying plants exudates, animals and microbial tissues at very low concentrations [26]. However, the use of tartaric acid for soil washing has generally not proven effective particularly for removal of $\mathrm{Pb}$ from contaminated soils. Removal efficiency have always been below $20 \%$ [2, 9, 27-29].

This study mainly focuses on enhancing usage of tartaric acid for soil-Pb decontamination. KCL modification of tartaric acid at different concentrations and washing time is applied on three soil types with different degree of contamination to evaluate lead removal efficiency.

\section{Experimental}

\subsection{Soil sampling and chemical analysis}

Three different soil types (sandy, clay and loamy) were sampled for the washing experiment from three different locations with obvious levels of contamination. Samples were collected by scooping about $12 \mathrm{~kg}$ soils each using a stainless steel into plastic bags. The samples were transferred to the laboratory where it was air dried and sieved through a $4 \mathrm{~mm}$ mesh size sieve. The three soil types were characterized for their physical properties and lead levels. Nitrate, phosphate, sulphate and soil $\mathrm{pH}$ were determined using hydrometric method in a 1:1 soil to water mixture [30], while flame photometric method was used for cation exchange capacity (CEC) [30]. 
Hydrometer method was used for soil mechanical properties [31], while the Walkley and Black method [32] was used for soil organic matter and organic carbon content. A $5.0 \mathrm{~g}$ portion each of soils was weighed into a glass beaker and digested with $50 \mathrm{~mL}$ portion of concentrated aqua regia $\left(\mathrm{HCl}\right.$ and $\mathrm{HNO}_{3}$ at ratio 3:1) mixture on a hot plate for $3 \mathrm{~h} \mathrm{[33]} \mathrm{to} \mathrm{obtain} \mathrm{the} \mathrm{pseudo-}$ total lead content. The pseudo-total lead was analyzed for all soil samples using a Varian SpectrAA-600 flame atomic absorption spectrophotometer (FAAS) after calibrating with Reagecon lead standard solutions.

\subsection{Chemical washing experiment}

The washing experiment was designed to improve lead removal efficiency of tartaric acid (TA) by modifying with $\mathrm{KCL}(\mathrm{KCl})$. In the experiment, $3 \%$ soil pulp density (SPD) was adopted which has been previous established to be effective [23]. A $0.3 \mathrm{~g}$ sandy soil was centrifuged with $10 \mathrm{~mL}(0.3 \mathrm{~g} / 10 \mathrm{~mL} \times 100=3 \% \mathrm{SPD}) 0.01 \mathrm{M}$ tartaric acid washing solution. They were sequentially agitated using a mechanical shaker (BOCH HY-BII Speed Governing Multipurpose Oscillator) at $172 \mathrm{rpm}$ for 2, 6, 12 and $24 \mathrm{~h}$. After agitation, the mixtures were centrifuged (BOSCH 80-2 centrifuge) at $2000 \mathrm{rpm}$ for $35 \mathrm{~min}$. The supernatants were extracted and stored for analysis. The washing step was repeated using $0.1,0.5$ and $1 \mathrm{M}$ tartaric acid washing solutions. The whole washing experiment was similarly repeated for clay and loamy soils. To enhance the washing efficiency, modified solutions of $10 \mathrm{~mL} \mathrm{TA} / 5 \% \mathrm{KCl}$ and $\mathrm{TA} / 10 \%$ $\mathrm{KCl}$ at 1:1 ratio (TA: $0.01,0.1,0.5$, and $1 \mathrm{M}$ ) were applied on each soil type for 2, 6, 12 and $24 \mathrm{~h}$ agitation. The supernatants were analyzed for $\mathrm{Pb}$ using FAAS. All analysis was performed in triplicate and the results presented as average values. Split samples were incorporated for instrument data validation. Analar grade reagents were used for the experiment. Standard deviation of the triplicate analyses performed on the extracts from the batch washing experiments was about $5 \%$.

The percentage removal efficiency of $\mathrm{Pb}$ from the soils was calculated using an equation similar to the one earlier reported [23, 29, 34].

$$
\text { Removal Efficiency }(\%)=\frac{C 1 \times V 1}{C s \times M S} \times 100
$$

where $C_{1}$ and $C_{\mathrm{s}}$ are the concentrations of $\mathrm{Pb}$ in the supernatant $(\mathrm{mg} / \mathrm{L})$ and soil sample $(\mathrm{mg} / \mathrm{kg})$, determined using FAAS respectively. In addition, $V_{1}$ is the volume of supernatant $(\mathrm{L})$ and $M_{\mathrm{S}}$ is the weight of the soil $(\mathrm{kg})$ used for the washing experiment.

\section{Results and discussion}

\subsection{Soil characteristics}

Table 1 shows general characteristics of studied soils.

Table 1. General physio-chemical characteristics of studied soils

\begin{tabular}{|c|c|c|c|c|}
\hline S/N & Parameter & Sandy & Loamy & Clay \\
\hline 1 & pH value & 6.17 & 8.18 & 7.79 \\
\hline 2 & Sand (\%) & 92.8 & 64.9 & 74.2 \\
\hline 3 & Clay (\%) & 1.43 & 12.8 & 25.0 \\
\hline 4 & Silt (\%) & 5.77 & 22.3 & 0.80 \\
\hline
\end{tabular}

\begin{tabular}{|c|c|c|c|c|}
\hline S/N & Parameter & Sandy & Loamy & Clay \\
\hline 5 & $\begin{array}{c}\text { Organic } \\
\text { carbon }(\%)\end{array}$ & 1.38 & 5.95 & 4.96 \\
\hline 6 & $\begin{array}{c}\text { Organic } \\
\text { matter }(\%)\end{array}$ & 2.39 & 10.3 & 8.58 \\
\hline 7 & $\begin{array}{c}\text { Nitrate } \\
(\mu \mathrm{g} / \mathrm{g})\end{array}$ & 8.39 & 185 & 84.3 \\
\hline 8 & $\begin{array}{c}\text { Phosphate } \\
(\mu \mathrm{g} / \mathrm{g})\end{array}$ & 5.64 & 37.6 & 21.2 \\
\hline 9 & $\begin{array}{c}\text { Sulphate } \\
(\mu \mathrm{g} / \mathrm{g})\end{array}$ & 110 & 238 & 164 \\
\hline 10 & $\begin{array}{c}\mathrm{CEC} \\
(\mu \mathrm{hms} / \mathrm{cm})\end{array}$ & 13.2 & 177 & 140 \\
\hline 11 & $\begin{array}{c}\mathrm{Lead} \\
(\mu \mathrm{g} / \mathrm{g})\end{array}$ & $61.9 \pm 9.14$ & $22,247 \pm 23.9$ & $11,828 \pm 18.7$ \\
\hline
\end{tabular}

Soil $\mathrm{pH}$ values were $6.17,8.18$ and 7.79 for sandy, loamy and clay soils respectively. Soil $\mathrm{pH}$ is a critical factor in washing experiments, because it directly determines the mobility and solubility of metal ions, i.e. lower $\mathrm{pH}$ will tend to favor greater solubility of metals [35]. The soils have typical properties of sandy, loamy and clay soils in respect to mechanical properties, organic matter content, nitrate, phosphate, sulfate and cation exchange capacity $[6,23,24]$. These soil properties are generally characteristic of tropical geological environment of the Precambrian basement complex formations [36]. Sandy soil showed higher sand content $(92.8 \%)$ with low organic matter $(2.39 \%)$ and macro nutrient levels, has against loamy and clay soils. Porosity of the sandy soil, with slightly acidic $\mathrm{pH}$, low organic matter and cation exchange capacity, will result in poor retention capacity for metals hence amenable to remediation by soil washing [37]. On the other hand, properties of loamy and clay soils may hinder easy dissolution of metals, hence modification is essential for effective washing. With increasing susceptibility of soils to trace metal contamination, these different soil properties will inadvertently influence the degree of metal removal through application of chemical soil washing techniques and therefore need to be examined. Average lead levels within the studied soils were: sandy $-61.9 \pm 9.14 \mu \mathrm{g} / \mathrm{g}$; loamy - 22,247 $\pm 23.9 \mu \mathrm{g} / \mathrm{g}$ and clay $-11,828 \pm 18.7 \mu \mathrm{g} / \mathrm{g}$. Contamination levels were more pronounced for loamy and clay soils.

\subsection{Lead removal efficiency by tartaric acid}

Tartaric acid is not known to remove $\mathrm{Pb}$ efficiently from soils [9, 28, 29], however, combining washing solutions with other reagents slightly improves removal efficiency $[2,27]$. Variables such as tartaric acid concentration and washing time were applied on sandy, loamy and clay soils to assess impact of soil properties on $\mathrm{Pb}$ removal efficiency (Table 2).

Table 2. Removal efficiency of $\mathrm{Pb}(n=3)$

\begin{tabular}{|c|c|c|c|c|}
\hline \multirow{2}{*}{$\begin{array}{c}\text { Tartaric } \\
\text { acid } \\
\text { conc. }\end{array}$} & $\mathbf{5}$ Washing time (h) \\
\cline { 2 - 5 } & $\mathbf{2}$ & $\mathbf{6}$ & $\mathbf{1 2}$ & $\mathbf{2 4}$ \\
\hline Sandy soil \\
\hline $0.01 \mathrm{M}$ & 0 & $4.90 \pm 0.58$ & $12.7 \pm 0.85$ & $14.5 \pm 0.72$ \\
\hline $0.1 \mathrm{M}$ & 0 & $6.07 \pm 0.46$ & $26.0 \pm 0.67$ & $55.4 \pm 1.79$ \\
\hline $0.5 \mathrm{M}$ & 0 & $12.6 \pm 0.71$ & $58.8 \pm 0.25$ & $89.1 \pm 1.65$ \\
\hline $1 \mathrm{M}$ & 0 & $18.2 \pm 0.98$ & $67.1 \pm 0.66$ & $94.3 \pm 1.13$ \\
\hline Clay soil & \multicolumn{5}{|c|}{} \\
\hline $0.01 \mathrm{M}$ & $3.03 \pm 0.09$ & $5.73 \pm 0.33$ & $7.71 \pm 0.37$ & $9.69 \pm 0.46$ \\
\hline $0.1 \mathrm{M}$ & $5.78 \pm 0.14$ & $7.89 \pm 0.23$ & $12.9 \pm 0.85$ & $15.2 \pm 1.36$ \\
\hline $0.5 \mathrm{M}$ & $23.4 \pm 0.16$ & $24.6 \pm 0.56$ & $46.6 \pm 0.65$ & $46.4 \pm 0.63$ \\
\hline $1 \mathrm{M}$ & $26.6 \pm 0.43$ & $33.7 \pm 0.35$ & $66.73 \pm 0.27$ & $67.6 \pm 0.95$ \\
\hline
\end{tabular}




\begin{tabular}{|c|c|c|c|c|}
\hline \multirow{2}{*}{$\begin{array}{c}\text { Tartaric } \\
\text { acid } \\
\text { conc. }\end{array}$} & $\mathbf{4}$ & $\mathbf{6}$ & $\mathbf{1 2}$ & $\mathbf{2 4}$ \\
\cline { 2 - 5 } & $\mathbf{4}$ & \\
\hline Loamy soil & \multicolumn{5}{|c|}{ Washing time (h) } \\
\hline $0.01 \mathrm{M}$ & $5.33 \pm 0.13$ & $5.36 \pm 0.15$ & $9.13 \pm 0.38$ & $8.45 \pm 0.52$ \\
\hline $0.1 \mathrm{M}$ & $4.00 \pm 0.02$ & $8.63 \pm 0.15$ & $14.6 \pm 0.45$ & $14.0 \pm 0.31$ \\
\hline $0.5 \mathrm{M}$ & $20.1 \pm 0.65$ & $18.7 \pm 0.39$ & $29.9 \pm 0.78$ & $29.3 \pm 0.91$ \\
\hline $1 \mathrm{M}$ & $16.0 \pm 0.73$ & $29.7 \pm 0.43$ & $35.0 \pm 0.34$ & $36.8 \pm 1.97$ \\
\hline
\end{tabular}

$* n=$ number of extractions

Concentration of tartaric acid and washing time played significant roles on the amount of $\mathrm{Pb}$ removed from sandy soil. For instance, $0.5 \mathrm{M}$ and $1 \mathrm{M}$ tartaric acid washing solutions removed $58.8 \%$ and $67.1 \% \mathrm{~Pb}$ respectively in $12 \mathrm{~h}$, and $55.4 \%$ (for $0.1 \mathrm{M}$ ), $89.1 \%$ (for $0.5 \mathrm{M}$ ) and $94.3 \%$ (for $1 \mathrm{M}$ ) in $24 \mathrm{~h}$ washing. It thus appears that high concentration of TA at longer washing time results in higher degree of $\mathrm{Pb}$ removal from sandy soils. The relatively low $\mathrm{Pb}$ level $(61.9 \pm 9.14 \mu \mathrm{g} / \mathrm{g}), \mathrm{pH}$ (6.17), organic matter content $(2.39 \%)$, cation exchange capacity $(13.2 \mu \mathrm{hms} / \mathrm{cm})$ and finally porous nature of the sandy soil have significantly contributed to enhanced $\mathrm{Pb}$ removal. For clay soil, tartaric acid concentration and washing time play little role on $\mathrm{Pb}$ removal efficiency. Only for $1 \mathrm{M}$ tartaric acid solution, a removal efficiency of $66.7 \%$ at $12 \mathrm{~h}$ and $67.6 \%$ at $24 \mathrm{~h}$ washing time was reported. The concentration and time factor played no role for loamy soil with just about $30 \% \mathrm{~Pb}$ removal for $1 \mathrm{M}$ tartaric acid solution at 12 and $24 \mathrm{~h}$ washing time, compared to sandy and clay soils. Complex matrix of the loamy soil property coupled with high $\mathrm{Pb}$ content $(22,247 \mu \mathrm{g} / \mathrm{g})$ and $\mathrm{pH}(8.18)$ could explain the rather low $\mathrm{Pb}$ removal. Buffering effect of alkaline soil on weak organic acid like tartaric acid is known to affect solubilization of metals from soils $[1,9,38]$.

\subsection{Lead removal efficiency by modified tartaric acid}

Tables 3 and 4 shows $\mathrm{Pb}$ removal efficiency using tartaric acid solution modified with $5 \%$ and $10 \% \mathrm{KCl}$ at different concentrations and washing time.

Table 3. Removal efficiency of $\mathrm{Pb}$ using $5 \% \mathrm{KCl}$ modification $(n=3)$

\begin{tabular}{|c|c|c|c|c|}
\hline \multirow{2}{*}{$\begin{array}{c}\text { Tartaric } \\
\text { acid } \\
\text { conc. }\end{array}$} & \multicolumn{4}{|c|}{ Washing time (h) } \\
\hline & 2 & 6 & 12 & 24 \\
\hline \multicolumn{5}{|c|}{ Sandy soil } \\
\hline $0.01 \mathrm{M}$ & $15.6 \pm 0.25$ & $28.6 \pm 0.63$ & $48.4 \pm 0.37$ & $74.3 \pm 3.87$ \\
\hline $0.1 \mathrm{M}$ & $19.6 \pm 0.37$ & $37.7 \pm 0.85$ & $55.8 \pm 1.29$ & $81.8 \pm 4.01$ \\
\hline $0.5 \mathrm{M}$ & $27.2 \pm 0.16$ & $41.0 \pm 1.20$ & $64.6 \pm 2.14$ & $92.9 \pm 3.86$ \\
\hline $1 \mathrm{M}$ & $36.2 \pm 1.47$ & $56.4 \pm 1.16$ & $70.7 \pm 2.27$ & $97.9 \pm 1.36$ \\
\hline \multicolumn{5}{|l|}{ Clay soil } \\
\hline $0.01 \mathrm{M}$ & $3.99 \pm 0.08$ & $6.36 \pm 0.91$ & $11.4 \pm 0.89$ & $18.3 \pm 0.42$ \\
\hline $0.1 \mathrm{M}$ & $37.3 \pm 1.28$ & $39.6 \pm 1.26$ & $67.6 \pm 1.96$ & $80.0 \pm 2.92$ \\
\hline $0.5 \mathrm{M}$ & $47.1 \pm 2.58$ & $48.9 \pm 1.10$ & $72.4 \pm 1.35$ & $85.5 \pm 2.86$ \\
\hline $1 \mathrm{M}$ & $51.8 \pm 2.21$ & $55.5 \pm 1.57$ & $84.0 \pm 2.06$ & $96.2 \pm 3.46$ \\
\hline \multicolumn{5}{|c|}{ Loamy soil } \\
\hline $0.01 \mathrm{M}$ & $8.37 \pm 0.50$ & $9.02 \pm 0.95$ & $13.4 \pm 0.27$ & $16.6 \pm 0.86$ \\
\hline $0.1 \mathrm{M}$ & $14.4 \pm 0.42$ & $12.5 \pm 0.41$ & $28.1 \pm 1.08$ & $38.7 \pm 1.54$ \\
\hline $0.5 \mathrm{M}$ & $36.5 \pm 1.83$ & $46.9 \pm 1.30$ & $70.9 \pm 3.83$ & $76.7 \pm 3.00$ \\
\hline $1 \mathrm{M}$ & $23.0 \pm 1.31$ & $24.8 \pm 1.26$ & $54.6 \pm 1.65$ & $63.8 \pm 1.91$ \\
\hline
\end{tabular}

Table 4. Removal efficiency of $\mathrm{Pb}$ using $10 \% \mathrm{KCl}$ modification $(n=3)$

\begin{tabular}{|l|c|c|c|c|}
\hline \multirow{2}{*}{$\begin{array}{l}\text { Tartaric } \\
\text { acid } \\
\text { conc. }\end{array}$} & $\mathbf{4}$ & $\mathbf{6}$ & $\mathbf{1 2}$ & $\mathbf{2 4}$ \\
\cline { 2 - 5 } & Washing time (h) \\
\hline Sandy soil & \multicolumn{5}{|c|}{} \\
\hline $0.01 \mathrm{M}$ & $19.7 \pm 1.91$ & $43.1 \pm 1.31$ & $62.3 \pm 2.12$ & $80.1 \pm 0.61$ \\
\hline
\end{tabular}

\begin{tabular}{|c|c|c|c|c|}
\hline \multirow{2}{*}{$\begin{array}{l}\text { Tartaric } \\
\text { acid } \\
\text { conc. }\end{array}$} & \multicolumn{4}{|c|}{ Washing time (h) } \\
\hline & 2 & 6 & 12 & 24 \\
\hline $0.1 \mathrm{M}$ & $27.2 \pm 1.00$ & $38.3 \pm 1.63$ & $68.8 \pm 2.25$ & $87.5 \pm 1.15$ \\
\hline $0.5 \mathrm{M}$ & $30.1 \pm 1.86$ & $56.6 \pm 2.36$ & $78.4 \pm 0.85$ & $93.2 \pm 2.86$ \\
\hline $1 \mathrm{M}$ & $42.3 \pm 2.43$ & $68.0 \pm 2.10$ & $87.3 \pm 6.11$ & $96.7 \pm 2.80$ \\
\hline \multicolumn{5}{|l|}{ Clay soil } \\
\hline $0.01 \mathrm{M}$ & $5.81 \pm 0.34$ & $8.42 \pm 0.53$ & $12.5 \pm 0.15$ & $14.0 \pm 0.21$ \\
\hline $0.1 \mathrm{M}$ & $40.5 \pm 1.14$ & $58.6 \pm 1.81$ & $65.8 \pm 1.27$ & $70.9 \pm 2.24$ \\
\hline $0.5 \mathrm{M}$ & $46.2 \pm 1.07$ & $63.1 \pm 2.93$ & $75.5 \pm 3.13$ & $86.9 \pm 3.21$ \\
\hline $1 \mathrm{M}$ & $62.3 \pm 1.63$ & $72.1 \pm 2.55$ & $83.4 \pm 4.25$ & $97.2 \pm 2.11$ \\
\hline \multicolumn{5}{|c|}{ Loamy soil } \\
\hline $0.01 \mathrm{M}$ & $9.20 \pm 0.04$ & $10.7 \pm 0.42$ & $20.5 \pm 0.02$ & $25.0 \pm 0.30$ \\
\hline $0.1 \mathrm{M}$ & $20.8 \pm 0.26$ & $21.0 \pm 0.17$ & $32.1 \pm 0.05$ & $47.6 \pm 0.75$ \\
\hline $0.5 \mathrm{M}$ & $47.1 \pm 0.24$ & $59.9 \pm 1.92$ & $80.6 \pm 3.51$ & $82.1 \pm 3.58$ \\
\hline $1 \mathrm{M}$ & $33.4 \pm 0.87$ & $39.8 \pm 1.77$ & $66.2 \pm 0.42$ & $65.9 \pm 1.29$ \\
\hline
\end{tabular}

Modified $5 \% \mathrm{KCl} / \mathrm{TA}$ and $10 \% \mathrm{KCl} / \mathrm{TA}$ washing solutions apparently enhanced removal efficiency of $\mathrm{Pb}$ across the four concentrations and washing time for sandy soils compared to tartaric acid washings solution alone. The enhancement was achieved mostly for 12 and $24 \mathrm{~h}$ washing time for all concentrations. $0.5 \mathrm{M}$ and $1 \mathrm{M}$ tartaric acid solutions can efficiently remove $\mathrm{Pb}$ from relatively uncontaminated sandy soils, as shown in Table 1, but these high concentrations could have uncertain effect on the soil ecosystem. Modification of lower concentration of $0.01 \mathrm{M}$ tartaric acid solution which is more soil friendly, as shown in Figure 1, could enhance $\mathrm{Pb}$ removal of up to $74.3 \%$ and $80.1 \%$ at $24 \mathrm{~h}$ washing. Proportional increase in removal efficiency could be achieved with increasing washing time.

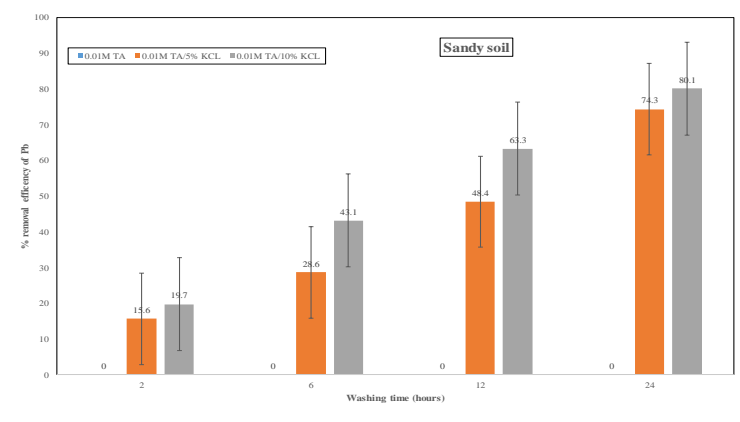

Figure 1. Removal efficiency of $\mathrm{Pb}$ in modified and unmodified $0.01 \mathrm{M}$ TA washing solution

For clay soils, $5 \% \mathrm{KCl}$ modification of $0.5 \mathrm{M}$ and 1 $\mathrm{M}$ tartaric acid solutions recorded significant enhanced removal efficiency across all washing time, attaining $96.2 \%$ for a concentration of $1 \mathrm{M}$ at $24 \mathrm{~h}$. The least removal efficiency was observed for $0.01 \mathrm{M}$ while for $0.1 \mathrm{M}$ attained over $60 \%$ for 12 and $24 \mathrm{~h}$ washing time. The high $\mathrm{Pb}$ level in clay soils, its complex matrix of organic macro nutrients and low concentration of $\mathrm{KCl}$ may account for the much needed high concentration tartaric acid for effective $\mathrm{Pb}$ removal. With $10 \% \mathrm{KCl}$ modification, $97.2 \%$ removal efficiency obtain with $1 \mathrm{M}$ tartaric acid solution at $24 \mathrm{~h}$. The $0.1 \mathrm{M}$ and $0.5 \mathrm{M}$ tartaric acid solutions also attained enhanced removal efficiency of over: $40 \%$ for $2 \mathrm{~h},>50 \%$ for $6 \mathrm{~h},>60 \%$ for $12 \mathrm{~h}$ and $>70 \%$ for $12 \mathrm{~h}$ washing. 


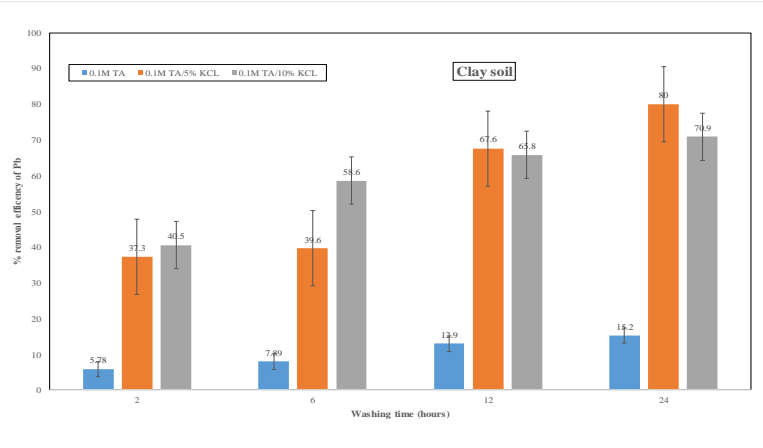

Figure 2. Removal efficiency of $\mathrm{Pb}$ in modified and unmodified $0.1 \mathrm{M}$ TA washing solution

From Figure 2, the weak unmodified 0.1 M TA washing solution is significantly enhanced with addition of $5 \%$ and $10 \% \mathrm{KCl}$ modification and washing time. As much as for other soils, loamy soils recorded the least enhanced removal efficiency when modifying TA with $5 \%$ and $10 \% \mathrm{KCl}$ (Tables 3 and 4). 5\% and $10 \% \mathrm{KCl}$ modified 0.5 and $1 \mathrm{M}$ tartaric acid solutions also showed enhancement especially for 12 and $24 \mathrm{~h}$ washing time. The highest attainable $\mathrm{Pb}$ removal efficiency is $76.7 \%$ for $5 \% \mathrm{KCl}$ and $82.1 \%$ for $10 \% \mathrm{KCl}$ at $24 \mathrm{~h}$ washing. The loamy soils had highest $\mathrm{Pb}$ level of 22,247 $\mu \mathrm{g} / \mathrm{g}$ which explains why modified $0.5 \mathrm{M}$ and $1 \mathrm{M}$ tartaric acid solutions had relatively low removal efficiency compared to clay and sandy soils.

Figure 3 shows the enhancement of $0.5 \mathrm{M}$ tartaric acid solution with respect to washing time. Longer washing time favored greater removal efficiency.

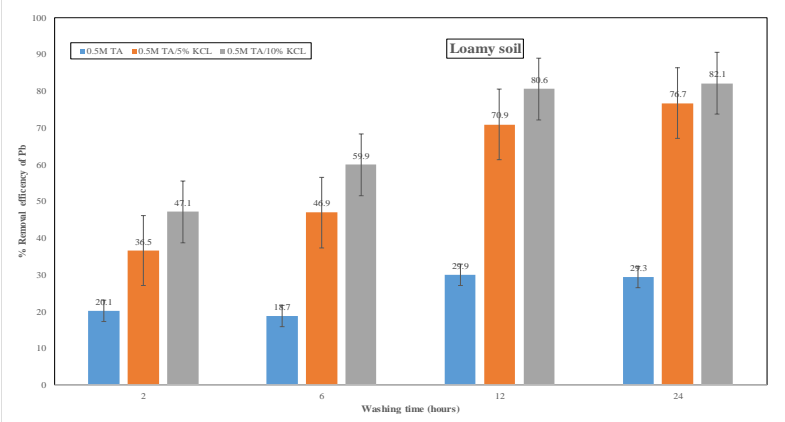

Figure 3. Removal efficiency of $\mathrm{Pb}$ in modified and unmodified $0.5 \mathrm{M}$ TA washing solution

The relationship between $\mathrm{Pb}$ removal efficiency and tartaric acid concentrations for the three soil types observed for $5 \% \mathrm{KCl}$ modification was also observed for $10 \% \mathrm{KCl}$ modification (Tables 3 and 4). However, $10 \% \mathrm{KCl}$ modifications were more efficient in removing $\mathrm{Pb}$ from the soils. The high salt concentration of $10 \%$ $\mathrm{KCl}$ washing solution substantially enhances the displacement of $\mathrm{Pb}$ from the soil crystalline lattice hence, responsible for enhancing $\mathrm{Pb}$ removal efficiency of $10 \% \mathrm{KCl} \mathrm{TA}$ washing solutions. Differences between lead and potassium in the activity series might explain a possible extraction mechanism, which involves initial dissolution of $\mathrm{Pb}$ pool from soils, and subsequently exchange with high concentration potassium cations from the $\mathrm{KCl}$ solutions. For the soils examined in this study, the effect of modification had negligible impact on $\mathrm{Pb}$ removal efficiency for $0.01 \mathrm{M}$ tartaric acid solution particularly in clay and loamy soils. These could well be attributed to high $\mathrm{Pb}$ levels and buffering capacity of those soils. In addition, increased washing time associated with elevated tartaric acid concentrations will eventually deplete buffering capacity of soils and under the present soil conditions (Table 1) concentration dependent solubilization of $\mathrm{Pb}$ will be achieved, since organic acids are known to decrease soil $\mathrm{pH}$ and form soluble complexes with trace metals [1]. In the washing experiment, $\mathrm{Pb}$ was removed from the soils with the following efficiency: $1 \mathrm{M}>0.5$ $\mathrm{M}>0.1 \mathrm{M}>0.01 \mathrm{M}$ TA with respect to increasing washing time, exception being $0.5 \mathrm{M}$ modified tartaric acid for loamy soil.

\section{Conclusion}

From the batch experiment study, tartaric acid has relatively weak removal efficiency of $\mathrm{Pb}$ particular from highly contaminated clay and loamy soils. However, for uncontaminated sandy soils, removal efficiency is as high as $94.3 \%$ for $1 \mathrm{M}$ tartaric acid washing solution at $24 \mathrm{~h}$ washing time which is very efficient. Generally, removal efficiency was observed to increase with increasing concentrations in most cases and also with increasing washing time. Modifications of the various concentrations of tartaric acid with $5 \%$ and $10 \% \mathrm{KCl}$ significantly enhanced $\mathrm{Pb}$ removal efficiency of 60$90 \%$, especially for 12 and $24 \mathrm{~h}$ washing time. Concentrations most significantly enhanced were 0.01 $\mathrm{M}, 0.1 \mathrm{M}, 0.5 \mathrm{M}$ and $1 \mathrm{M}$ for sandy, $0.1 \mathrm{M}, 0.5 \mathrm{M}$ and 1 $\mathrm{M}$ for clay, and $0.5 \mathrm{M}$ and $1 \mathrm{M}$ for loamy soils. Removal efficiency was in the following order: $1 \mathrm{M}>0.5 \mathrm{M}>0.1$ $\mathrm{M}>0.01 \mathrm{M}$ tartaric acid solution. Tartaric acid washing is promising and recommended in events of moderate contamination and $10 \% \mathrm{KCl}$ modification in event of high level contamination. Further study is needed on enhancing very low concentrations of tartaric acid for large scale applications.

\section{Conflict of interest}

The author declares no conflict of interest.

\section{References}

[1]. S. Yuan, Z. Xi, Y. Jiang, J. Wan, C. Wu, Z. Zheng, $\mathrm{X}$. Lu, Desorption of copper and cadmium from soils enhanced by organic acids, Chemos. 68 (2007) 1289-1297.

[2]. J. Wang, J. Jiang, D. Li, K. Li, S. Tian, Removal of $\mathrm{Pb}$ and $\mathrm{Zn}$ from contaminated soil by different washing methods: The influence of reagent and ultrasound, Environ. Sci. Pollut. Res. 22 (2015) 20084-91.

[3]. D.H. Moon, J. Park, A. Koutsospyros, K.H. Cheong, Y. Chang, K. Back, R. Jo, J. Park, Assessment of soil washing for simultaneous removal of heavy metals and low-level petroleum hydrocarbons using various washing solutions, Environ. Earth Sci. 75 (2016) 884-892.

[4]. Center for Disease Control and Prevention (CDC). Notes from the field: Outbreak of acute $\mathrm{Pb}$ poisoning among children aged $<5$ years-Zamfara, 
Nigeria. (2010). Morbidity Mortality Weekly 59 (2010) 846-847.

[5]. M. Soleimani, M.A. Hajabbasi, M. Afyumi, S. Akbar, J.K. Jensen, P.E. Holm, O.K. Borggaard, Comparison of natural humic substances and synthetic ethylenediamineacetic acid and nitrilotriacetic acid as washing agent of heavy metal-polluted soils, J. Environ. Quality 39 (2010) 855-863.

[6]. E.U. Etim, P.C. Onianwa, Lead contamination of soil in the vicinity of a military shooting range in Ibadan, Nigeria, Toxicol. Environ. Chem. 94 (2012) 895-905.

[7]. Z.M. Gusiatin, E. Klimiuk, Metal (Cu, Cd and Zn) removal and stabilization during multiple soil washing by saponin, Chemos. 86 (2012) 383-391.

[8]. B.I. Olu-Owolabi, P.N. Diagboya, W.C. Ebaddan, Mechanism of $\mathrm{Pb}^{2+}$ removal from aqueous solution using a nonliving moss biomass, Chemical Eng. J. 195-196 (2012) 270-275.

[9]. G. Zhu, Q. Guo, J. Yang, H. Zhang, R. Wei, C. Wang, M. Peters, X. Zhou, J. Yang, Washing out heavy metals from contaminated soils from an iron and steel smelting site, Frontier Environ. Sci. Eng. 9 (2015) 634-641.

[10]. G. Dermont, M. Bergeron, G. Mercier, M. RicherLafleche, Soil washing for metal removal: A review of physical/chemical technologies and field applications, J. Hazard. Mater. 152 (2008) 1-31.

[11]. D.C.W. Tsang, I.M.C. Lo, Competitive $\mathrm{Cu}$ and $\mathrm{Cd}$ sorption and transport in soils: a combined batch kinetics, column, and sequential extraction study, Environ. Sci. Tech. 40 (2006) 6655-6661.

[12]. J.S. Yang, J.Y. Lee, K. Baek, T.S. Kwon, J. Choi, Extraction behavior of $\mathrm{As}, \mathrm{Pb}$, and $\mathrm{Zn}$ from mine tailings with acid and base solutions, J. Hazard. Mater. 171(2009) 443-451.

[13]. D.H. Moon, J. Lee, M. Wazne, J. Park, Assessment of soil washing for $\mathrm{Zn}$ contaminated soils using various washing solutions, J. Ind. Eng. Chem. 18 (2012) 822-825.

[14]. D. Voglar, D. Lestan, Pilot-scale washing of metal contaminated garden soil using EDTA, J. Hazard. Mater. 215-216 (2012) 32-39.

[15]. E.U. Etim, Batch washing of lead contaminated and spiked soils using water extracts of dried Terminalia mantaly, Panicum maximum and Eleusine indica plants, Ovidius University Ann. Chem. 30 (2019) 29-36.

[16]. S. Ehsan, S.O. Prasher, W.D. Marshall, A washing procedure to mobilize mixed contaminants from soil: Heavy metals, J. Environ. Quality 35 (2006) 2084-2091.

[17]. Y. Li, P. Hu, J. Zhao, C. Dong, Remediation of cadmium- and lead contaminated agricultural soil by composite washing with chlorides and citric acid, Environ. Sci. Pollut. Res. 22 (2014) 55635571.

[18]. D. Voglar, D. Lestan, Chelant soil-washing technology for metal contaminated soil, Environ. Tech. 35 (2014) 1389-1400.

[19]. C. Chen, Y. Chen, T. Xie, M.K. Wang, G. Wang, G. Removal, redistribution, and potential risk of soil $\mathrm{Cd}, \mathrm{Pb}$, and $\mathrm{Zn}$ after washing with various extractants, Environ. Sci. Pollut. Res. 22 (2015) 16881-16888.

[20]. A.P. Schwab, D.S Zhu, M.K. Banks, Influence of organic acids on the transport of heavy metals in soil, Chemos. 72 (2008) 986-994

[21]. J. Wen, S.P. Stacey, M.J. McLaughlin, J.K. Kirby, Biodegradation of rhamno lipid, EDTA and citric acid in cadmium and zinc contaminated soils, Soil Biology Biochem. 41 (2009) 2214-2221.

[22]. Y. Chen, S. Zhang, X. Xu, P. Yao, T. Li, G. Wang, G. Gong, Y. Li, O. Deng, Effects of surfactants on low molecular weight organic acids to wash soil zinc, Environ. Sci. Pollut. Res. 23 (2016) 4629 4638.

[23]. E.U. Etim, Lead removal from contaminated shooting range soil using acetic acid KCL washing solutions and electrochemical reduction, J. Health Pollut. 7 (2017) 22-31.

[24]. E.U. Etim, Batch leaching of Pb-contaminated shooting range soil using citric acid-modified washing solution and electrochemical reduction, Inter. J. Environ. Sci. Tech. 16 (2019) 3013-3020.

[25]. S. Wang, C.N. Mulligan, Effects of three lowmolecular-weight organic acids (LMWOAs) and $\mathrm{pH}$ on the mobilization of arsenic and heavy metals $(\mathrm{Cu}, \mathrm{Pb}$, and $\mathrm{Zn})$ from mine tailings, Environ. Geochem. Health. 35 (2013) 111-118.

[26]. K.H. Tan, Degradation of soil minerals by organic acids. In: Huang, P.M. and Schnitzer, M. (Eds.). Interactions of soil minerals with natural and microbes. Soil Science Society of America. Special Publication No. 17, Madison, Wisconsin, USA. Pp: 1-27 (1986).

[27]. S.A. Wasay, S. Barrington, S. Tokunaga, Organic acids for the in-situ remediation of soils polluted by heavy metals: Soil flushing in columns, Water, Air Soil Pollut. 127 (2000) 301-314.

[28]. K.E. Xin, L. Pei-Jun, Z. Qi-Xing, Z. Yun, S. TieHeng, Removal of heavy metals form contaminated soil using tartaric acid, J. Environ. Sci. 18 (2006) 727-733.

[29]. R.A. Wuana, J.A. Okieimen, J.A. Imborvungu, Removal of heavy metals form a contaminated soil using organic chelating acids, Inter. J. Environ. Sci. Tech. 7 (2010) 485-496.

[30]. International Institute of Tropical Agriculture, (IITA), Selected methods for soil and plant analysis. Manual Series No. 1. IITA, Ibadan (2001).

[31]. G.H. Bouyoucos, A recalibration of the hydrometer for making mechanical analysis of soils, Agron. J. 43 (1951) 434-438.

[32]. A. Walkley, I.A. Black, An examination of the Degtjareff method for determining soil organic matter and proposed modification of the chromic acid titration method, Soil Sci. 37 (1934) 29-38.

[33]. H. Niskavaara, C. Reimann, V. Chekushin, G. Kashulina, Seasonal variability of total and easily leachable element contents in top soils $(0-5 \mathrm{~cm})$ from eight catchments in the European Arctic (Finland, Norway and Russia), Environ. Pollut. 96 (1997) 261-74. 
[34]. K.R. Reddy, S. Chinthamreddy, Comparison of extractants for removing heavy metals from contaminated clayey soils, Soil Sed. Contam. 9 (2000) 449-462.

[35]. S. Tokalioglu, S. Kartal, A. Gultekin, Investigation of heavy metal uptake by vegetables growing in contaminated soils using the modified BCR sequential extraction method, Inter. J. Environ. Analy. Chem. 85 (2006) 417-430.

[36]. C.N. Okezie, Geological map of Nigeria. Div. Geological Survey. Lagos, Nigeria (1985).

[37]. Z. Atafar, A.R. Mesdaghinwa, J. Nouri, M. Homaee, M. Yunesian, M. Ahmadimoghaddam,
A.H. Mahvi, Effect of fertilizer application on soil heavy metal concentration, Environ. Monit. Assess. 160 (2010) 83-89.

[38]. S. Bisone, J. Blais, P. Drogui, G. Mercier, Toxic metal removal from polluted soil by acid extraction, Water, Air Soil Pollut. 223 (2012) 3739-3755.

Received: 04.03.2020

Received in revised form: 09.04.2020

Accepted: 11.04.2020 